\title{
Impacts of Resource Dispersing and Resource Directing Task Dimensions on EFL Learners' Oral Production
}

\author{
Elham Ansari ${ }^{1} \&$ Sajad Shafiee ${ }^{2}$ \\ ${ }^{1}$ Department of English, Isfahan (Khorasgan) Branch, Islamic Azad University, Isfahan, Iran \\ ${ }^{2}$ Department of English, Shahrekord Branch, Islamic Azad University, Shahrekord, Iran \\ Correspondence: Sajad Shafiee, Department of English, IAU, Shahrekord Branch, Shahrekord, Iran. E-mail: \\ s.shafiee@iaushk.ac.ir
}

Received: March 1, 2018 Accepted: June 2, 2018 Online Published: August 22, 2018

doi:10.5539/ijel.v8n6p148 URL: https://doi.org/10.5539/ijel.v8n6p148

\begin{abstract}
This study was primarily aimed at investigating the effects of simultaneous use of reasoning demand (resource-directing) and prior knowledge (resource-dispersing) on fluency, accuracy, and complexity of L2 oral performance. More, specifically, an attempt was made to investigate how EFL oral production could be affected by \pm reasoning demand and \pm prior knowledge in the local context of Iran. Thirty male and female Iranian intermediate EFL learners whose mother tongue was Persian and whose age ranged between 23 and 29 were chosen as the participants in this study, and a pretest-posttest quasi-experimental design was utilized. Assigned to two experimental conditions, participants were engaged in a narrative task in which two different wordless picture stories were chosen for data collection. Such statistical operations as $t$ tests and MANOVA were applied to analyze the data. The results obtained from $t$ tests revealed that in \pm reasoning demand condition, both complexity and accuracy significantly improved whereas the results for fluency were not statistically significant. In addition, with regard to the \pm prior knowledge group, similar results were obtained. In the end, conducting MANOVA revealed that both groups were not different in the pretest; however, utilizing the same procedure for the posttest illustrated a difference between the two groups in terms of their accuracy and complexity, but not their fluency. The results bear some implications for L2 oral production and practice as controlled by teachers and practitioners in EFL contexts.
\end{abstract}

Keywords: reasoning demand, prior knowledge, accuracy, fluency, complexity

\section{Introduction}

Tasks have been seen by many authors as a primary unit of instruction and/or as building blocks of classroom language learning over the past couple of decades (e.g., Bygate, Skehan, \& Swain, 2001; Ellis, 2003; Long, 1989; Skehan, 1998). The growing interest in task-based language teaching (TBLT) and learning has largely been motivated by the fact that tasks lay foundations for second language (L2) use and acquisition. Task-based language teaching is a contemporary and trendy approach to L2 teaching that could be deemed as a strong version of communicative language teaching (Ellis, 2003). A good number of L2 researchers and practitioners have contended that, compared to lexical units, topics, or grammatical constructions, tasks are a valid alternative unit upon which a syllabus can be built (e.g., Long 1989; Skehan, 1996).

In second language acquisition (SLA) research, tasks have been widely and frequently used as a way to draw attention to interactional features, negotiation of meaning, input processing, noticing forms, and language production, all of which are believed to promote L2 learning (e.g., Bygate, et al., 2001). As Skehan (1996) maintains, enhancing L2 learning is related to the improvement of three main areas or dimensions of performance: accuracy, complexity, and fluency. Skehan views accuracy as concerned with "a learner's capacity to handle whatever level of interlanguage complexity he or she has currently attained" (1996, p. 46). It may thus be safe to claim that encouraging learners to produce language more accurately promotes the use of controlled rather than automatic processes. Additionally, since automatic processes develop out of controlled processes (McLaughlin \& Heredia, 1996), accuracy is considered to be indispensable for the way language develops and becomes automatic. Skehan also holds that complexity pertains to "the stage and elaboration of the underlying interlanguage system" (1996, p. 46). According to Ellis and Barkhuizen (2005), 'elaborated language' could be conceived of in two different senses: First, cutting edge development of the learner language, which is not yet 
fully automatic, and second, learners' readiness to use a wide range of linguistic structures. They also maintain that complexity is a function of learners' enthusiasm to try out new linguistic knowledge in their spoken or written productions. Fluency, Skehan adds, "Concerns the learner's capacity to mobilize an interlanguage system to communicate meaning in real time" (1996, p. 46). In fact, when learners are producing more fluent language, they are prioritizing meaning over form (Ellis \& Barkhuizen, 2005).

The Cognition Hypothesis posits that sequencing tasks from simple to complex provides the optimal conditions for language practice, engendering gains in automaticity, inasmuch as it facilitates the executive processes of scheduling, and coordinating the component demands of complex tasks (Rubinstein, Meyer, \& Evans, 2001; Sanders, 1998). One of the ways in which this can be achieved is by progressively cutting back on the relevant prior knowledge a learner can draw on in performing tasks. Doing so can bring about two other branches of high prior knowledge and low prior knowledge both of which are well worth of being investigated. Boosting monologic task complexity along \pm prior knowledge leads to a reduction of attentional and memory resources which could decrease complexity, accuracy, and fluency on more complex tasks.

On the other hand, reasoning demand within the task complexity framework is seen as one of the variables in the resource-directing continuum which has attracted an enormous amount of ink among L2 researchers (e.g., Iwashita, McNamara \& Elder, 2001). Reasoning demand can be defined as the extent to which learners are required to provide justifications, reasons, and explain causalities (Candlin \& Murphy, 1987; Nunan, 1989; Skehan, 1996). This being so, a task with high reasoning demand (+ reasoning demand) would require learners to immensely involve in reasoning processes to complete the task, whereas in low reasoning demand (-Reasoning demand) learners are supposed to describe and talk about something rather than providing reasons. Robinson (2005) hypothesized that increasing the reasoning demand of a task can augment the use of syntactic complementation (i.e., learners might need to use logical connectors and cognitive verbs) to provide reasons.

The general goal of this experiment is to test the impact of resource-dispersing and resource-directing task dimensions (i.e., reasoning demands \& prior knowledge) on the oral performance (CAF) of Iranian intermediate EFL learners. Considering the aforementioned issues, this study addressed the following research questions and null hypotheses:

1) Does reasoning demand have any significant effects on Iranian EFL learners' oral proficiency?

2) Does prior knowledge have any significant effects on Iranian EFL learners' oral proficiency?

3) Is there any significant difference between \pm reasoning demand and \pm prior knowledge in terms of their effect on Iranian EFL learners' oral proficiency?

Hypotheses are formulated as follows:

1) Reasoning demand does not have any significant effects on the Iranian EFL learners' complex production.

2) Reasoning demand does not have any significant effects on the Iranian EFL learners' accurate production.

3) Reasoning demand does not have any significant effects on the Iranian EFL learners' fluent production.

4) Prior knowledge does not have any significant effects on the Iranian EFL learners' complex oral production.

5) Prior knowledge does not have any significant effects on the Iranian EFL learners' accurate oral production.

6) Prior knowledge does not have any significant effects on the Iranian EFL learners' fluent oral production.

7) There is not any significant difference between reasoning demand and prior knowledge in terms of their effect on Iranian EFL learners' complex production.

8) There is not any significant difference between reasoning demand and prior knowledge in terms of their effect on Iranian EFL learners' accurate production.

9) There is not any significant difference between reasoning demand and prior knowledge in terms of their effect on Iranian EFL learners' fluent production.

\section{Literature Review}

\subsection{Theoretical Framework}

This study is formed within current SLA theories of task complexity, and it attempts to investigate the impacts of manipulating several task factors on task performance in a single experimental study. In order to situate the relevant research, an attempt was made to review the two recent opposing theoretical frameworks on task complexity in TBLT research: On the one hand, Skehan and Foster's Limited Capacity Model (LCM) (The single-resource model) and Robinson's Cognition Hypothesis ( $\mathrm{CH}$ ) (Multiple-resource model) on the other hand. 
According to the limited capacity model, for L2 learners, a trade-off is at work between attention to form and attention to meaning during task performance. More precisely, Skehan and Foster (2001) assumed that processing task content and task performance demands are in constant competition with one another. Hence, more complex tasks will demand more attention to content, and correspondingly, leave less room for attention to language. Based on the Limited Capacity Model, Skehan (1998) and Skehan and Foster $(1999,2001)$ held that cognitively demanding language tasks are opt to draw attentional resources away from language forms. Consequently, cognitively demanding language tasks are likely to negatively affect accuracy. Contrary to Skehan's limited capacity model (1996), Robinson (2007) proposed that with respect to attention and task complexity, learners are able to access multiple and non-competitional pools of attention. Robinson's cognition hypothesis gives rise to a framework for describing task complexity by means of which sequencing decisions may be operationalized, which predicts that increasing task complexity would boil down to greater linguistic complexity and higher accuracy. Robinson (2007) identified the features of tasks which contribute to task complexity in his Triadic Componential Framework.

In the Triadic Componential Framework (presented in Table 1), Robinson puts forward a three-dimensional model that distinguishes between three different types of factors: cognitive complexity factors (resource-directing ones including [ + / Here-and-Now], [ $+/$ - few elements], and [ $+/-$ no reasoning demands]; resource-dispersing ones such as [+/_ planning], [+/- single task], and [+/_ prior knowledge]); interactive factors (participation variables such as one way/two way, convergent/divergent, open/closed; participant variables such as gender, familiarity, power/solidarity); and leaner factors (affective variables such as motivation, anxiety, and confidence; ability variables such as aptitude, proficiency, and intelligence).

Table 1. A triad of task complexity, task conditions, and task difficulty factors (Robinson, 2005)

\begin{tabular}{|c|c|c|}
\hline $\begin{array}{l}\text { Task complexity } \\
\text { (Cognitive factor) }\end{array}$ & $\begin{array}{l}\text { Task condition } \\
\text { (Interactive factors) }\end{array}$ & $\begin{array}{l}\text { Task difficulty } \\
\text { (Learner factors) }\end{array}$ \\
\hline (a) Resource-directing & (a) Participation Variable & (a) Affective variables \\
\hline \pm few elements & Open/closed & Motivation \\
\hline \pm here and now & One- way/two- way & Anxiety confidence \\
\hline \pm reasoning demands & Convergent/divergent & \\
\hline (b) Resource-dispersing & (b) Participant variable & (b) Ability variables \\
\hline tplanning time & Gender familiarity & Aptitude \\
\hline \pm single task & Power/solidarity & Working memory \\
\hline \pm prior knowledge & & Intelligence \\
\hline
\end{tabular}

With regard to task complexity, there are two important perspectives, resource-directing and resource dispersing, which are believed to influence task performance and learning substantially. The resource-directing dimensions pose conceptual demands, whereas the resource-dispersing dimensions pose procedural demands on the learners. In the triadic task complexity framework offered by Robinson, the resource-directing dimensions include whether the task requires learners to make reference to events in the past or events in the present, whether the task requires learners to make reference to few or many elements, and whether the task requires learners to use spatial reasoning or not.

The resource-dispersing dimensions include whether or not planning time is given to learners, whether or not prior knowledge is provided in the task, and whether a single task or multiple tasks are carried out concurrently by learners. Robinson contends that the proliferation of task complexity with respect to the resource-directing dimensions (e.g., \pm here and now, \pm reasoning demands, \pm few elements) would bring about more accurate and complex oral production as learners have to attend to the conceptual or functional demands of the task, but would lead to lower fluency, as learners have to deliberately and explicitly process language. In contrary, it is shown that an increase in task complexity with regard to the resource-dispersing dimensions (e.g., \pm planning time, \pm prior knowledge, and \pm single task) would result in less fluent, less accurate, and less complex oral production since the learners' attention would not be directed to any particular aspects of the linguistic system to meet the increased task demands. It is discussed in the literature that increasing task demands with regard to the resource-dispersing dimension would restrict the attentional and working memory resources of learners and divert them away from concentration on critical aspects of solving the task. This would not only lead to a reduction of the learners' attentional and memory resources, but also result in impoverished task performance (Gilbert, 2007; Kuiken \& Vedder, 2007; Robinson, 2003, 2005). 
Skehan (1998) and Robinson (2001a, 2005, 2007) are not in line with each other in their predictions of the effects of increasing cognitive demands of tasks with respect to resource-directing factors on language production. Whereas Skehan (1998) believes that increasing task complexity respecting these factors causes reduced fluency, complexity, and accuracy of oral language production, Robinson (2005) argues that increasing task complexity with respect to these factors augments complexity and accuracy but reduces fluency.

\subsection{Empirical Studies}

\subsubsection{Research on Planning Time}

Robinson, Ting, and Urwin (1995) studied the impact of task complexity on learners' written complexity, accuracy, and fluency. In their work, the manipulated variable was \pm planning time. L1 English learners of high intermediate level Mandarin Chinese were requested to describe a number of pictures in the written manner under either the (- planning time) condition, wherein participants were not provided time to plan their written report, or in the (+planning time) context, wherein three minutes of pre-task planning were allocated. Accuracy was measured by the target-like use of verb morphology, measure words, and tense markers. However, Fluency was gauged by means of the length of written production, measured in words and T-units. In spite of such potential limitations, Robinson et al. observed no significant difference between (+planning) and (-planning) on either accuracy or fluency. Such findings were in contrast with the predictions of the Cognition Hypothesis.

Under Robinson's (2001b, 2005) framework, variables in resource dispersing column namely ( \pm planning time) are predicted to affect the production (accuracy and fluency) negatively. The obtained findings were in stark contrast with Skehan and Foster's, who likewise predicted negative influences on production.

Robinson et al.'s research, moreover, investigated the efficacy of \pm planning time on participants' oral production, through the same picture sequences. Participants' oral production indicated a subtle difference in the findings in comparison to the results of written investigation. Although no task effects were found for accuracy in the oral description, as in the written description, fluency measured by number of words was found to be significantly different among task conditions. That is, those in the less complex task condition had extra fluent speech (based on the number of words). Fluency measured by number of utterances, however, was not affected by task complexity. The oral production version of the picture sequence task does not present full support for either Skehan and Foster's or Robinson's models, as both models predict detrimental effects on accuracy and fluency.

\subsubsection{Research on \pm Single Task}

Robinson (2007) investigated \pm single factor, a resource-dispersing factor. L1 Dutch university students $(n=20)$ were asked to read a computerized German text wherein they were able to click on unknown words with their mouse. Leaners were randomized into four conditions, yet all participants read the same German text and completed a number of vocabulary and comprehension tests. The cognitive complexity of the task was considered to be determined by the task instructions. In condition one, learners were trained to respond a vocabulary test according to the words from the text (no mention of the comprehension test was made to participants). In condition two, subjects were informed to be given a reading comprehension test subsequent to reading the text (with no indication that vocabulary tests would also follow). As for condition three, participants were aware prior to reading the text that both vocabulary and comprehension tests would be given to them. In condition four, the control group, participants were not provided any instructions rather than read the text. Peters considered those in the third condition to be performing a dual task-single task and as a consequence the most complex task since based on his words, such subjects were forced to divide their attentional resources between both comprehension and vocabulary.

To provide answer to research question one investigating the impact of task complexity on reading comprehension, the results point to a significant difference only between the second group (one of the purported single task conditions) and control group. Interestingly, there was not any significant difference between +complex and-complex tasks on the comprehension scores. With respect to the effect of task complexity on vocabulary acquisition, no significant effects were found either. Peters attributes the lack of significant differences to the small size of the sample. The methodological concern here, though, as Peters later points out, is that the four groups may not have behaved very differently. That is, instructions that prompt learners to focus on one particular aspect (e.g., just vocabulary) does not necessarily cause learners to focus on just that aspect. Learners who read the German text knowing that they were going to be tested on vocabulary, for example, may have also focused on the content of the text, making it more similar to the dual task 3 . Similarly, those in the second condition who read the text knowing they were going to have a reading comprehension test was probably very similar to the control group, who, although was not told they would have a comprehension test, still likely processed the text for meaning. Despite the limitations, the results seemed to provide evidence for Skehan's 
(1998) competition model.

Using ten intermediate learners of English, Robinson et al. (1995) manipulated cognitive complexity by the \pm single task variable. In the -complex tasks, single task condition, participants were provided with a city map with the route from A to B marked. In the +complex task, -single task condition, participants were provided with the same map, but the route was not marked. Such final condition was considered to be a dual task since participants were forced to diagnose the route themselves, and also orally illustrated how to get to the destination at the same time. Robinson et al. examined how task complexity influenced fluency (number of pauses and number of words per utterance), accuracy (amount of embeddings or S-nodes in each utterance), and complexity in terms of lexical density (proportion of new to old words used on the task). They found that the more complex task -single task led to significantly decreased fluency (on both fluency measures), but had no effect for accuracy nor complexity. The results on fluency support the predictions made by the Limited Capacity Attention Model and the Cognition Hypothesis, but those on accuracy and complexity do not. Although both of the above tasks are conceivably miscellaneous, it was claimed that +complex task was not really a dual task in the traditional sense of the word. In other words, participants potentially looked ahead prior to the provision of directions. The fact that + complex aspect resulted in higher pauses lends credence to the idea that participants were potentially looking ahead prior to the provision of a set of directions. If this interpretation is acceptable, then finding and describing the route does not occur simultaneously, as dual tasks require. In order to explore the effects of \pm single task conditions, research needs to employ tasks that are really single versus dual.

\subsubsection{Research on \pm Prior Knowledge}

With regard to another subcategory of resource-dispersing column, tprior knowledge on L2 listening comprehension, Robinson et al. (1995) randomized beginner participants of Mandarin Chinese into three groups. Group one $(n=11)$ finished a pre-listening task whose focus was on form (i.e., the organization of lectures). In that task, the researchers concentrated on the organization of lectures by eliciting participants' attention to tools for sequencing the ideas in Chinese lectures and the overall organization of a lecture. Group two $(n=11)$ moreover performed the same task, yet the one whose focus was on a topic concerning the topic of the treatment listening task (i.e., tourism in Beijing). However, group three $(n=7)$ was a control group who was not provided with any prior information with regard to the form or content of the treatment lecture. All groups then heard a tape-recorded lecture about tourism in part of China. A multiple-choice comprehension test was employed to assess the subjects, wherein subjects were requested to give answer to questions with regard to the facts of the lecture and requested to make inferences on the basis of the information heard. No negative results were indicated for - prior knowledge condition, as would have been expected in Skehan's and Robinson's models. Instead, subjects were statistically better able to make inferences in +prior knowledge condition. There were no significant task complexity effects on learners' recall.

\subsubsection{Research on \pm Few Elements}

As a part of a more extended research, Kuiken and Vedder (2007) conducted some manipulations with regard to task complexity on two resource-directing factors: \pm few elements and - no reasoning demands. Native Dutch-speaking university students $(n=76)$ learning French conducted two L2 (French) writing tasks. In both experimental conditions, participants had to select a holiday destination (out of a choice of five options) and write a letter to their friend explaining their choice -no reasoning demands, which Robinson (2007) called causal reasoning. In the supposed "non-complex" task, subjects were granted three requirements to consider their selection of vacation, and in the "complex" task, six necessities were requisite \pm few elements. Hence, three versus six criteria differentiated the complexity of the task 4 . Motivated by the outcomes of a pilot study they had conducted where cognitive complexity seemed to be affected by the level of proficiency, Kuiken and Vedder decided to include language proficiency as a variable.

Kuiken and Vedder (2007) results were that cognitive complexity influences different dimensions of linguistic output (operationalized as accuracy, syntactic complexity, and lexical variation) distinctly. Respecting accuracy, learners made statistically fewer mistakes (for first and second degree errors as well as the total number of errors per T-unit) in the more complex task than in the less complex one. In terms of syntactic complexity, no differences between tasks were found in terms of either the number of clauses per T-unit or the degree of syntactic embedding per clause. And with regard to lexical variation, the more complex task elicited more lexical variation in one of the measures (when the number of word types was divided by the total number of word tokens) than the less cognitively demanding task. When examining whether language proficiency was a moderating variable, Kuiken and Vedder found that the effects of task complexity were not related to language proficiency. 
Generally, such an investigation does not lend any support to Skehan and Foster's Limited Attentional Capacity Model, as the claim of the current model is worse performance on more complex task. Rather, Kuiken and Vedder (2007) explored better results on +complex task. Interestingly, there is partial support to Robinson's Cognition Hypothesis. To put it differently, while +complex task (manipulated on a resource-directing dimension) did draw better results in some parts and measures, syntactic complexity and one of the measures of lexical variation which does the correction for text length indicated no task impacts.

Another larger study was conducted by Kuiken, Mos, and Vedder (2005) whose methodology resembled the study of Kuiken and Vedder (2007) based on firstly the dimensions of the task complexity namely \pm single task and -no reasoning, secondly the employed writing tasks, thirdly the separation of participants into two levels of proficiency through a cloze test, together with the operationalization of L2 performance and its measures. The major modification with Kuiken et al. (2005) is that they examined the effect of task complexity using, not students of French, but rather 62 university students of Italian. The statistical analyses indicated no significant task effect on syntactic complexity nor lexical variation, but a difference did exist for accuracy: learners in the more complex task were more accurate in their written production. This last result was moderated by proficiency level, however, in that the higher proficiency learners had better performance on three of the four types of accuracy measures, and lower proficiency learners did better on the other measure of accuracy. As Kuiken, et al. (2005) explained, the lack of task differences in lexical variation and syntactic complexity did not provide evidence in support of either the Limited Attentional Capacity Model or the Cognition Hypothesis, as the former would have predicted better results for the less complex task, and the latter, the more complex task. The only support for any of these frameworks is in terms of accuracy, where the Cognition Hypothesis predicts that the more complex task would lead to greater accuracy.

As for the comparison of the current findings with that of Kuiken and Vedder (2007), employing the same tasks and measures, slight differences can be observed. Both found task effects for $100 \%$ accuracy (+complex task resulted in better accuracy) and had no influence for syntactic complexity, but the picture on lexical variation was blurred. Concerning lexical variation, Kuiken and Vedder discovered that +complex task draws more lexical variation for one measure but not the other (this measure reveals no difference between task complexity conditions), and Kuiken et al. found no task effects at all for lexical variation. Additionally, whereas the study with the French students found proficiency level not to play a role at all, the study with the Italian learners found that it moderated accuracy performance. These varying results are quite interesting given that they are based on the same tasks, manipulated in the same way across studies. This suggests that task complexity is a more complex picture than set forth in the models of Skehan and Foster and Robinson or that the operationalization or measurement of task complexity is not methodologically robust.

\subsubsection{Research on \pm Here-and-Now}

In one of the studies of Robinson, Ting, and Urwin (1995), the variable [+/- here-and- now] was examined in an oral narrative task. They cite their motivation for examining [+/- here-and-now] as coming from evidence from child L1 acquisition and adult SLA research. In this body of research, there is evidence that "past time reference to events dislocated in time and space is a more effortful and later developed ability than present tense reference to contextualized events" (Robinson et al., 1995, p. 66). Twelve intermediate learners of English were given a series of cartoon strips and were asked to narrate the events of the cartoon in the present tense, while the strip was present (the [+ here-and-now] condition), and in the past tense, when the strip (a different strip) was removed (the [- here-and-now] condition).

The +complex condition, There-and-Then, resulted in higher accuracy (target-like use of articles) and lexical density (proportion of new words to old words), yet there exists less fluency (in words per utterance). No significant task effects existed for syntactic complexity (S-nodes per T-unit) or fluency, as measured by number of pauses. Such findings approximately deviate from the principles of Robinson's subsequently formed as Cognition Hypothesis. The +complex task led to higher accuracy and complexity and less fluent speech, according to Cognition Hypothesis, yet the linguistic complexity effects were restricted to lexical density and did not include syntactic complexity.

Furthermore, the effects of fluency were restricted to words per utterance, not number of pauses. Skehan and Foster's Limited Attentional Capacity Model would have predicted decreased performance on all the measures above; therefore, Skehan and Foster's model is not fully supported either.

Ishikawa (2007) investigated the efficacy of the manipulation of task complexity on the resource-directing column, \pm here-and-now subcategory on L2 written narrative discourse. Japanese participants $(\mathrm{N}=54)$ in year three of high school watched a cartoon strip and afterwards provided a written L2 narrative in English. Subjects 
in the group of there-and now provided them with the cartoon strip within the process of the writing task. Participants in -here-and-now group did not have the chance of viewing cartoon strip subsequent to five-minute viewing immediately before beginning the L2 written narrative. Ishikawa investigated the effects of task complexity on accuracy (using 3 measures), structural complexity (4 measures), lexical complexity (4 measures), and fluency ( 3 measures).

Ishikawa (2007) discovered that when task conditions are statistically different, participants being involved in +complex task, -here-and now factor, obtained higher performance than-complex task, there-and-now group. Such significant findings were found for one of the measures of accuracy, all of the measures of structural complexity (but none for lexical complexity), and two of the measures of fluency. Regardless of the significant main effects, a number of significant interactions were likewise known. The interactions were between task complexity and proficiency (as measured by the Michigan English Placement Test), and they indicated that on two of the measures of fluency and two of the measures of lexical complexity, participants with low-to intermediate proficiency scored higher on the more complex task.

Ishikawa argued that overall, the results seem to suggest that the more complex task condition was able to direct learners' attention to accuracy, complexity, and fluency without trade-off effects between accuracy and complexity, which he indicated goes against Skehan's (1996) predictions. Ishikawa considered his results to be more compatible with the predictions of Robinson's Cognition Hypothesis, where increases in cognitive and conceptual demands of tasks along resource-directing dimensions have positive effects on L2 production. There seems to be, however, an aspect not supported by the Cognition Hypothesis that Ishikawa does not address - that of fluency. Robinson (2005) argues that: Increasing complexity along resource-directing dimensions can be expected to lead the learner to map the increasing conceptual/functional requirements of tasks onto speech, in such a way as to affect fluency negatively, but, in selected domains, to facilitate the development of increased accuracy and complexity of production. (p. 7, italics my own).

In Ishikawa's study, participants in the more complex task performed better than the less complex task learners on two of the three measures of fluency. No explanation is offered as to why these results do not support Robinson's predictions regarding fluency. I would attribute that to Robinson's lack of explanation as to why fluency should be negatively affected in the first place. Also, are Robinson's predictions regarding fluency expected to be the same across modality (oral vs. written) Cognitive constraints in the oral mode appear to be different from those in the written mode. Additionally, the Cognition Hypothesis does not support the lack of statistical difference on two of the measures of lexical complexity, but as Ishikawa indicates, these findings were based on errors made, and perhaps the methodological validity of measuring errors is questionable. Reviewing the studies cited above justifies conducting the present study in the context of Iran where the simultaneous effects of resource directing and resource dispersing task dimensions of the oral ability of EFL learners were not previously investigated.

\section{Methods}

The primary objective of the current study was to explore how certain aspects of learners' oral performance (i.e., complexity, accuracy, and fluency) could be affected by reasoning demand and prior knowledge. To find answers to the research questions of the study, a quasi-experimental design was picked up, and the research was conducted in an educational context with already formed English language teaching classes and addressed the issue of competition for attention i.e. the effect of manipulating task complexity on students' oral CAF. As for independent variables, two levels have been defined which are reasoning demands and prior knowledge whereas there was the set of three analytic measures (dependent variables) of fluency, complexity, and accuracy. Both $t$ test and MANOVA were employed to figure out the effects of the independent variables on the dependent variables and also to discover the differences between the participating groups of learners.

\subsection{Participants}

There were 30 Iranian learners of English, both males and females, participating in the study. They were learning English as a foreign language at Faraz English Language Institute in Isfahan, Iran. The participants' mother tongue was Persian, and their age ranged between 23 and 29. They were studying American English File 4 and therefore, their English proficiency level was considered to be intermediate. In order to make sure about the homogeneity of the participants, an Oxford Quick Placement Test (OQPT) version 1 was utilized. According to the level chart of the OQPT, those students whose scores fell between 30 and 47 were considered intermediate. Therefore, it could be claimed that all the participants were at the same proficiency level. 


\subsection{Instruments}

To meet the objectives of the study, the following instruments and materials were exploited: First, subsequent to convenience sampling (in order to choose the participants of the study), the learners received an OQPT (version 1), which comprised 60 multiple-choice items consisting of grammar (20 items), vocabulary (20 items), and reading comprehension (20 items). The allotted time for answering the questions was 30 minutes. A multiple-choice test format was considered to be appropriate for Iranian learners who have had much experience taking tests in a similar format during formal schooling. For the purpose of the present study, four picture stories were chosen as the materials for data collection. The reason why different picture stories were chosen was to avoid the practice effect from pretest to posttest. To compensate for the negative effect of participants' knowledge on the selected topics on their oral performance, care was exercised to choose those picture stories with every day subjects. The pictures employed in this research were thought to be especially useful for doing this experiment as they were wordless comic strips, and included a few characters who were involved in the depicted actions, and the stories had a vivid climax. They referred to situations all students could supposedly be familiar with within their cultural parameters. In other words, with the main focus of the investigation being on the effects of resource directing and resource dispersing task dimensions on learners' spoken production, the study used a series of picture narration tasks as such tasks had been used in previous studies investigating reasoning demand conditions (e.g., Gilabert, 2007; Robinson, 2001a, 2001b, 2005, 2007). Each sequence of ten pictures was taken from the Mr. Bean television program. While all the participants knew the character of Mr. Bean, none were familiar with the particular stories portrayed in the picture sets.

\subsection{Procedure}

As mentioned above, the participants were selected based on their performance on the OQPT. Having conducted the proficiency test, the researchers randomly assigned the participants to two groups of 15 since there were two conditions for the independent variables i.e., \pm reasoning demands and \pm prior knowledge. As for \pm reasoning demands, the condition was operationalized as follows:

Under the +reasoning demands conditions, the intervening pictures were scrambled so that the participants had to sequence them before narrating, whereas under the -reasoning demands conditions, the pictures were presented to the participants in the correct sequence. To make sure that the participants understood the task, they were given a simple set of practice pictures to narrate before the main experiment. These practice sets showed simple, everyday actions, like checking out at a grocery store, frying an egg, or doing school homework. A brief account of the condition under which the picture sets were to be narrated then ensued, so the participants knew well the required steps they had to take in the \pm reasoning demand conditions. Following these instructions, there was no interaction between the researchers and participants, rendering these tasks monologic. At the onset of the procedure, participants in the first group ( \pm reasoning demand) performed the six-picture photo all parts of which were in the correct order (-reasoning demands).

However, as for the posttest, the same participants were provided with the same photo with the only difference that the intervening six pictures were all scrambled, so the participants had to sequence them before narrating. Participants were initially given 60 seconds to take a look at the picture and with the picture in their hands, they narrated a six-picture photo related to Mr. Bean and the conflicts he had in the waiting room. In order to avoid any practice effects, a two-week interval were allotted between the pretest (-reasoning demand) and posttest (+reasoning demands).

As for the second condition, \pm prior knowledge, the participants were initially pretested in order to obtain their level of proficiency. It should be stated that here -prior knowledge task i.e., a structure of the narrative about playing golf (which was schematically unfamiliar) was given to the participants for the pretest. Having done that, for the posttest which happened two weeks later (to stop any further practice effect), the researchers gave them a photo with a series of schematically familiar scripts, about which participants had already had some schemata i.e., the structure of a narrative about classroom. Here again, they were allowed 60 seconds to look at the photo and while having the photo in their hands, they presented the story based on the above-defined conditions. It is worth noting that the operationalization of \pm prior knowledge condition was based on Skehan and Foster (1999).

\section{Results}

This study was an attempt to investigate the effects of reasoning demands and prior knowledge on the oral production of EFL learners. Results are presented in the following order. First, the results of $t$ test will be reported for the three aspects of performance (fluency, complexity and accuracy) with regard to each independent variable (i.e., reasoning demands and prior knowledge) in both the pretest and posttest sessions. Subsequently, to discover the difference between the two groups and understand which group outperformed the 
other, the results of MANOVA are presented.

\subsection{The Effect of Reasoning Demand on the Complexity, Accuracy, and Fluency of Oral Production}

The first research question addressed the effect of reasoning demand on complexity, accuracy, and fluency of upper intermediate EFL learners' oral production in the treatment (pretest \& posttest). In response to this question, hypotheses one, two, and three were formulated.

Hypothesis 1: Reasoning demands do not have any significant effects on the Iranian EFL learners' oral complexity. Table 2 shows the descriptive statistics of the scores of complexity before the treatment (pretest) and after the treatment (posttest).

Table 2. Descriptive statistics of compering pretest and posttest scores of complexity

\begin{tabular}{llllll}
\hline & & Mean & $N$ & $S t d$. Deviation & $S t d$. Error Mean \\
\hline \multirow{2}{*}{ Pair1 } & PRE-COM-RD & 27.43 & 15 & 10.07 & 2.60 \\
& POST-COM-RD & 38.00 & 15 & 7.02 & 1.81 \\
\hline
\end{tabular}

As can be seen in Table 2, the means and standard deviation of the pretest and posttest are different. In order to find out whether the mean differences are statistically significant or not, $t$ test was employed. The results of $t$ test, illustrated in Table 3 below, show that there was a statistically significant difference in the scores for pretest $(M$ $=27.43, S D=10.07)$ and posttest $(M=38.00, S D=7.02) ; t(14)=-3.51, p=.003$. Consequently, the first hypothesis was disconfirmed; to put it differently, it can be claimed that reasoning demands significantly improved the complexity of upper intermediate Iranian EFL learners' oral production.

Table 3. Compering pretest and posttest scores of complexity

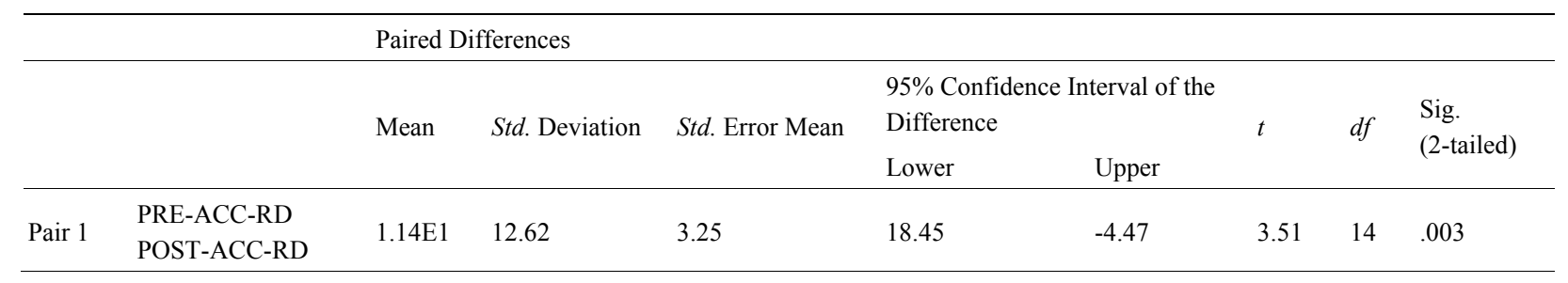

Hypothesis 2: Reasoning demands do not have any significant effect on the Iranian EFL learners' oral accuracy. To answer the above question, a table of descriptive statistics (Table 4) was provided for both pretest and posttest in which both mean and the standard deviation are seen to be different.

Table 4. Descriptive statistics of compering pretest and posttest scores of accuracy

\begin{tabular}{llllll}
\hline & Mean & $N$ & Std. Deviation & Std. Error Mean \\
\hline \multirow{2}{*}{ Pair 1} & PRE-ACC-RD & 26.76 & 15 & 9.03 & 2.33 \\
& POST-ACC-RD & 33.63 & 15 & 10.95 & 2.82 \\
\hline
\end{tabular}

As it is apparent, owing to the above disparity between the means of the pretest and posttest with regard to accuracy, $t$ test was required to be used in order to see if the disparity between the two means is statistically significant or not. In other words, $t$ test results illustrated that there was a significant difference in the scores of reasoning demands on accuracy from pretest $(M=26.76, S D=2.33)$ to posttest $(M=33.63, S D=10.95) ; t(14)$ $=-2.7 \cdot p=.015$. As a result, the second research hypothesis was also disconfirmed. 
Table 5. Comparing pretest and posttest scores of accuracy

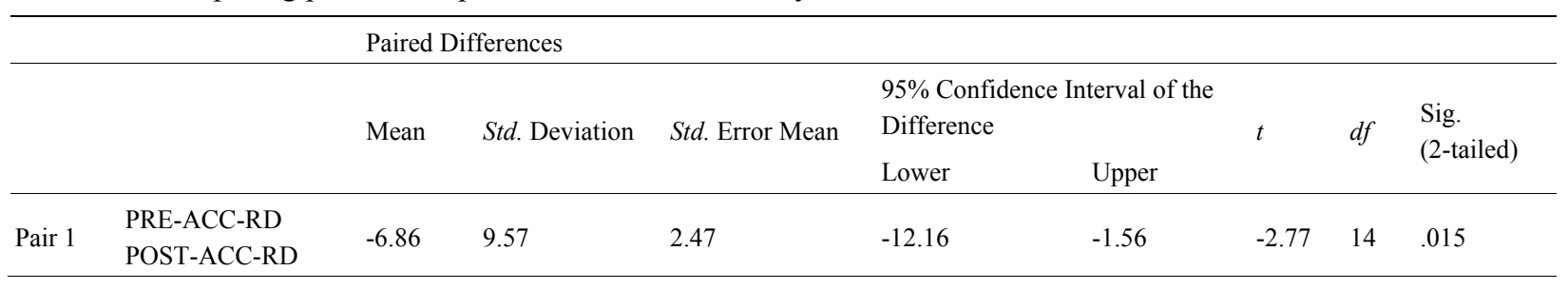

Hypothesis 3: Reasoning demands do not have any significant effects on the Iranian EFL learners' oral fluency. To provide the answer to this hypothesis, a table of descriptive statistics was provided for both pretest and posttest in which both mean and the standard deviation are seen to be different. By referring to Table 6, one can see that the mean for pretest $(M=15.06)$ was smaller than that of posttest $(15.20)$; therefore, in order to realize if the disparity is statistically significant, $t$ test was applied.

Table 6. Descriptive statistics of compering pretest and posttest scores of fluency

\begin{tabular}{llllll}
\hline & Mean & $N$ & $S t d$. Deviation & Std. Error Mean \\
\hline \multirow{2}{*}{ Pair 1} & PRE-FLU-RD & 15.06 & 15 & 3.45 & .89 \\
& POST-FLU-RD & 15.20 & 15 & 3.98 & 1.02 \\
\hline
\end{tabular}

Based on the calculation of $t$ test in the following table, it is revealed that regarding fluency, the dissimilarity between the two means from pretest to posttest was not statistically significant at the probability level of $p$ $=.58$. As a result, the null hypothesis claiming "no difference exists in the fluency of Iranian EFL learners' oral production under reasoning demands" is retained.

Table 7. Comparing pretest and posttest scores of fluency

\begin{tabular}{|c|c|c|c|c|c|c|c|c|c|}
\hline & & \multicolumn{8}{|c|}{ Paired Differences } \\
\hline & & \multirow{3}{*}{ Mean } & \multirow{3}{*}{ Std. Deviation } & \multirow{3}{*}{ Std. Error Mean } & \multirow{2}{*}{\multicolumn{2}{|c|}{$\begin{array}{l}95 \% \text { Confidence Interval of the } \\
\text { Difference }\end{array}$}} & \multirow{3}{*}{$t$} & \multirow{3}{*}{$d f$} & \multirow{3}{*}{$\begin{array}{l}\text { Sig. } \\
(2 \text {-tailed) }\end{array}$} \\
\hline & & & & & & & & & \\
\hline & & & & & Lower & Upper & & & \\
\hline \multirow{2}{*}{ Pair 1} & PRE-FLU-RD & \multirow{2}{*}{-.13} & \multirow[t]{2}{*}{.91} & \multirow{2}{*}{.23} & \multirow{2}{*}{-.64} & \multirow[t]{2}{*}{.37} & \multirow{2}{*}{-.56} & \multirow[t]{2}{*}{14} & \multirow[t]{2}{*}{.58} \\
\hline & POST-FLU-RD & & & & & & & & \\
\hline
\end{tabular}

\subsection{The Effect of Prior Knowledge on the Complexity, Accuracy, and Fluency of Oral Production}

The second research question was relevant to the effect of prior knowledge on complexity, accuracy, and fluency of Intermediate EFL learners' oral production before the treatment (pretest) and subsequent to the treatment (posttest). To provide a response to this question, hypotheses four, five, and six were formulated which were investigated as follows.

Hypothesis 4: Prior knowledge does not have any significant effects on Iranian EFL learners' oral complexity. In order to find a response to the above question, a table of descriptive statistics was provided for both pretest and posttest in which both mean and the standard deviation are seen to be different. By referring to Table 8, one can see that the mean for pretest $(M=30.4)$ was lower than that of posttest (41.7); therefore, in order to see if the difference is statistically significant, $t$ test was employed.

Table 8. Descriptive statistics of compering pretest and posttest scores of complexity

\begin{tabular}{llllll}
\hline & Mean & $N$ & Std. Deviation & Std. Error Mean \\
\hline \multirow{2}{*}{ Pair 1 } & PRE-COM-PK & 30.43 & 15 & 8.20 & 2.11 \\
& POST-COM-PK & 41.70 & 15 & 13.45 & 3.47 \\
\hline
\end{tabular}


On the basis of the conducted $t$ test in the following table (Table 9), it is illustrated that with regard to complexity, the difference between the two means from pretest to posttest was statistically significant at $p<.05$ level of significance. As a result, the null hypothesis stating "no difference exists in the complexity of Iranian EFL learners' oral production because of the effect of prior knowledge" is disconfirmed. To put it differently, the results of the conducted $t$ test revealed that a significant difference avails in the scores of prior knowledge on complexity from pretest $(M=30.4, S D=8.20)$ to posttest $(M=41.7, S D=13.45) ; t(14)=-2.75 . p=.011$. In short, the fourth hypothesis was rejected.

Table 9. Comparing pretest and posttest scores of complexity

\begin{tabular}{|c|c|c|c|c|c|c|c|c|c|}
\hline & & \multicolumn{8}{|c|}{ Paired Differences } \\
\hline & & \multirow{3}{*}{ Mean } & \multirow{3}{*}{ Std. Deviation } & \multirow{3}{*}{ Std. Error Mean } & \multirow{2}{*}{\multicolumn{2}{|c|}{$\begin{array}{l}95 \% \text { Confidence Interval of the } \\
\text { Difference }\end{array}$}} & \multirow{3}{*}{$t$} & \multirow{3}{*}{$d f$} & \multirow{3}{*}{$\begin{array}{l}\text { Sig. } \\
\text { (2-tailed) }\end{array}$} \\
\hline & & & & & & & & & \\
\hline & & & & & Lower & Upper & & & \\
\hline \multirow[t]{2}{*}{ Pair 1} & PRE-COM-PK & -1.12667 & \multirow[t]{2}{*}{15.82} & \multirow[t]{2}{*}{4.08} & \multirow[t]{2}{*}{-20.03} & \multirow[t]{2}{*}{-2.50} & \multirow[t]{2}{*}{-2.75} & \multirow[t]{2}{*}{14} & \multirow[t]{2}{*}{.011} \\
\hline & POST-COM-PK & E1 & & & & & & & \\
\hline
\end{tabular}

Hypothesis 5: prior knowledge does not have any significant effects on Iranian EFL learners' oral accuracy. As Table 10 shows, with regard to the effect of prior knowledge on accuracy, the mean scores of the pretest and posttest were compared.

Table 10. Descriptive statistics of compering pretest and posttest scores of accuracy

\begin{tabular}{llllll}
\hline & Mean & $N$ & $S t d$. Deviation & Std. Error Mean \\
\hline \multirow{2}{*}{ Pair 1 } & PRE-ACCU-PK & 30.26 & 15 & 8.19 & 2.11 \\
& POST-ACCU-PK & 37.33 & 15 & 8.12 & 2.09 \\
\hline
\end{tabular}

As it is evident here, there is a disparity between the mean of pretest $(M=30.26)$ and the posttest $(37.33)$. In order to see whether the disparity between the two means is statistically significant before and after the treatment, $t$ test was employed. As demonstrated in Table 11, the results of the $t$ test illustrated that there is a statistically significant difference between the pretest $(M=30.26, S D=8.19)$ and posttest $(M=37.3, S D=8.12) ; t(14)=$ -3.47. $p=.004$ regarding the effect of prior knowledge on oral accuracy. Therefore, hypothesis five predicting that prior knowledge does not have any significant effect on the Iranian EFL learners' oral accuracy is disapproved.

Table 11. Comparing pretest and posttest scores of accuracy

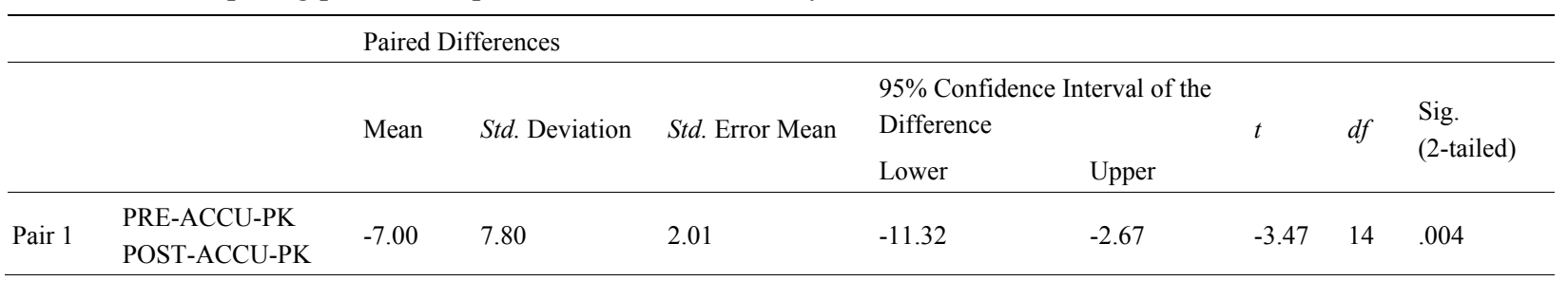

Hypothesis 6: Prior knowledge does not have any significant effects on Iranian EFL learners' oral fluency. Table 12 shows the descriptive statistics of the scores of fluency before the treatment (pretest) and after the treatment (posttest).

Table 12. Descriptive statistics of compering pretest and posttest scores of fluency

\begin{tabular}{llllll}
\hline & Mean & $N$ & $S t d$. Deviation & Std. Error Mean \\
\hline \multirow{2}{*}{ Pair 1 } & PRE-FLU-PK & 12.83 & 15 & 3.86 & .99 \\
& POST-FLU-PK & 12.63 & 15 & 3.44 & .88 \\
\hline
\end{tabular}


As can be seen in Table 12, the means and standard deviations of the pretest and posttest are different. In order to see if the mean differences are statistically significant, $t$ test was run. Based on the obtained results in Table 13, there is no statistically significant difference at the $p<.05$ level of significance regarding the effect of prior knowledge on fluency from pretest to posttest. Consequently, the sixth hypothesis is retained; in other words, it can be contended that prior knowledge does not assist the fluency of intermediate Iranian EFL learners' oral production.

Table 13. Comparing pretest and posttest scores of fluency

\begin{tabular}{|c|c|c|c|c|c|c|c|c|c|}
\hline & & \multicolumn{8}{|c|}{ Paired Differences } \\
\hline & & \multirow{3}{*}{ Mean } & \multirow{3}{*}{ Std. Deviation } & \multirow{3}{*}{ Std. Error Mean } & \multirow{2}{*}{\multicolumn{2}{|c|}{$\begin{array}{l}95 \% \text { Confidence Interval of the } \\
\text { Difference }\end{array}$}} & \multirow{3}{*}{$t$} & \multirow{3}{*}{$d f$} & \multirow{3}{*}{$\begin{array}{l}\text { Sig. } \\
\text { (2-tailed) }\end{array}$} \\
\hline & & & & & & & & & \\
\hline & & & & & Lower & Upper & & & \\
\hline Pair 1 & $\begin{array}{l}\text { PRE-FLU-PK } \\
\text { POST-FLU-PK }\end{array}$ & .20 & .56 & .14 & -.11 & .51 & 1.38 & 14 & .189 \\
\hline
\end{tabular}

\subsection{Differences among the Two Groups of Reasoning Demands and Prior Knowledge Regarding CAF}

The third research question addressed if there were any differences between reasoning demands and prior knowledge in terms of their effects on Iranian EFL learners' oral proficiency. In order to check the null hypotheses, MANOVA was used to understand whether any differences existed between the two groups before and after the treatment. Descriptive statistics (i.e., the means, minimum and maximum scores, and standard deviations) were calculated for pretest in this study. Table 14 illustrates the results of the descriptive statistics for reasoning demands and prior knowledge. As it can be observed, there were some differences between the two groups in terms of complexity, accuracy, and fluency, which might be attributable to reasoning demands and prior knowledge.

Table 14. Descriptive statistics of pretest

\begin{tabular}{llllll}
\hline & $N$ & Minimum & Maximum & Mean & Std. Deviation \\
\hline Group & 30 & 1.00 & 2.00 & 1.50 & .50 \\
PRE-COM-RD & 15 & 15.00 & 45.00 & 27.43 & 8.20 \\
PRE-ACC-RD & 15 & 15.00 & 45.00 & 26.76 & 8.20 \\
PRE-FLU-RD & 15 & 6.00 & 23.00 & 15.06 & 3863 \\
PRE-COM-PK & 15 & 15.00 & 45.00 & 30.43 .53 & 8.20 \\
PRE-ACC-PK & 15 & 10.00 & 21.00 & 30.26 & 8.19 \\
PRE-FLU-PK & 15 & 10.00 & 21.00 & 12.83 & 3.86 \\
Valid N (listwise) & 0 & & & & \\
\hline
\end{tabular}

To discover if any significant differences existed between the two groups, MANOVA was performed. Before performing any statistical analysis on the data set, the homogeneity of variances was checked and the results are depicted in Table 15.

Table 15. Test of homogeneity variances for pretest

\begin{tabular}{llll}
\hline Pretest & & & \\
\hline Levene Statistic & $d f 1$ & $d f 2$ & Sig. \\
1.13 & 2 & 87 & .35 \\
\hline
\end{tabular}

The result of Levene's test of homogeneity was not significant $(p>.05)$, which means that the assumption of homogeneity of variance was not violated. Having performed the MANOVA, we needed to look at the second effect and the results of the Wilks' Lambda, based on which it can be stated that there was not a statistically significant difference between reasoning demands and prior knowledge groups in the pretest, $F(3,26)=2.424, p$ $=.088 ;$ Wilk's $=.781$. 
Table 16. Multivariate test results for the pretest

\begin{tabular}{|c|c|c|c|c|c|c|}
\hline Effect & & Value & $F$ & Hypothesis $d f$ & Error $d f$ & Sig. \\
\hline \multirow[t]{4}{*}{ Intercept } & Pillai's Trace & .969 & $2.665 \mathrm{E} 2^{\mathrm{a}}$ & 3.00 & 26.00 & .000 \\
\hline & Wilks' Lambda & .031 & $2.665 \mathrm{E} 2^{\mathrm{a}}$ & 3.00 & 26.00 & .000 \\
\hline & Hotelling's Trace & 30.75 & $2.665 \mathrm{E} 2^{\mathrm{a}}$ & 3.00 & 26.00 & .000 \\
\hline & Roy's Largest Root & 30.75 & $2.665 \mathrm{E} 2^{\mathrm{a}}$ & 3.00 & 26.00 & .000 \\
\hline \multirow[t]{4}{*}{ Group } & Pillai's Trace & .219 & $2.424^{\mathrm{a}}$ & 3.00 & 26.00 & .088 \\
\hline & Wilks' Lambda & .781 & $2.424^{\mathrm{a}}$ & 3.00 & 26.00 & .088 \\
\hline & Hotelling's Trace & .280 & $2.424^{\mathrm{a}}$ & 3.00 & 26.00 & .088 \\
\hline & Roy's Largest Root & .280 & $2.424^{\mathrm{a}}$ & 3.00 & 26.00 & .088 \\
\hline
\end{tabular}

In order to test the last three hypotheses of the study, hypothesizing that there is no difference between the reasoning demands and prior knowledge in terms of complexity, accuracy and fluency, another MANOVA was run. The results of the descriptive statistics for the two groups of the study are shown in Table 17.

Table 17. Descriptive statistics of posttest

\begin{tabular}{llllll}
\hline & $N$ & Minimum & Maximum & Mean & Std. Deviation \\
\hline Group & 30 & 1.00 & 2.00 & 1.50 & .50 \\
POST-COM-RD & 15 & 25.00 & 55.00 & 38.00 & 8.12 \\
POST-ACC-RD & 15 & 20.00 & 69.00 & 33.63 & 13.45 \\
POST-FLU-RD & 15 & 6.00 & 21.00 & 15.20 & 3.44 \\
POST-COM-PK & 15 & 15.00 & 46.00 & 41.00 & 10.95 \\
POST-ACC-PK & 15 & 25.00 & 55.00 & 37.33 & 7.02 \\
POST-FLU-PK & 15 & 10.00 & 23.00 & 12.63 & 3.98 \\
Valid N (listwise) & 0 & & & & \\
\hline
\end{tabular}

The results showed that the mean scores of the EFL learners in two groups of reasoning demands and prior knowledge in posttest were dissimilar. In order to detect whether differences could reach statistical significance or not, the assumption of the homogeneity of variances was first checked (Table 18), and then a MANOVA (Table 19) was run:

Table 18. Test of homogeneity variances for posttest

\begin{tabular}{llll}
\hline Posttest & & & \\
\hline Levene Statistic & $\mathrm{df1}$ & $\mathrm{df} 2$ & Sig. \\
4.34 & 2 & 87 & .16 \\
\hline
\end{tabular}

As demonstrated in Table 18, the result of Levene's test of homogeneity did not reach the level of significance ( $p$ $=.16>.05)$. This denotes that there was no violation of the assumptions of homogeneity of variance in the obtained results. The result of the MANOVA is exhibited in Table 19.

Table 19. Multivariate test results for the posttest

\begin{tabular}{|c|c|c|c|c|c|c|}
\hline Effect & & Value & $F$ & Hypothesis $d f$ & Error $d f$ & Sig. \\
\hline \multirow[t]{4}{*}{ Intercept } & Pillai's Trace & .983 & 5.13 & 3.00 & 26.00 & .000 \\
\hline & Wilks' Lambda & .017 & 5.13 & 3.00 & 26.00 & .000 \\
\hline & Hotelling's Trace & 59.24 & 5.13 & 3.00 & 26.00 & .000 \\
\hline & Roy's Largest Root & 59.24 & 5.13 & 3.00 & 26.000 & .000 \\
\hline \multirow[t]{4}{*}{ Group } & Pillai's Trace & .694 & 19.64 & 3.00 & 26.00 & .000 \\
\hline & Wilks' Lambda & .306 & 19.64 & 3.00 & 26.00 & .000 \\
\hline & Hotelling's Trace & 2.26 & 19.64 & 3.00 & 26.00 & .000 \\
\hline & Roy's Largest Root & 2.26 & 19.64 & 3.00 & 26.00 & .000 \\
\hline
\end{tabular}


Subsequent to the performance of MANOVA, one needs to look at the second effect and the results of the Wilks' Lambda, based on which it can be stated that there was a statistically significant difference between reasoning demands and prior knowledge groups in the posttest, $F(3,26)=19.64, p=.000$; Wilk's Lambda $=.306$. In order to pinpoint the exact location of the difference between the two conditions (i.e., to find out whether the two conditions differed with respect to complexity, accuracy, or fluency), the post hoc test results (as shown in Table 20) had to be examined:

Table 20. Tests of between-subjects effects

\begin{tabular}{lllllll}
\hline & & Type III Sum of & & & \\
& Dependent Variable & Squares & $d f$ & Mean Square & $F$ & Sig. \\
\hline \multirow{2}{*}{ Group } & Accuracy & 886.55 & 1 & 886.55 & 17.04 & .00 \\
& Complexity & 593.33 & 1 & 593.33 & 12.87 & .00 \\
& Fluency & 14.85 & 1 & 14.85 & .127 & .72 \\
\hline
\end{tabular}

Table 20 revealed the fact that among the three measures of CAF, there were significant differences between the two groups with respect to their accuracy and complexity. However, their oral fluency did not turn out to be significantly different from one another.

\section{Discussion}

This research study attempted to investigate the effects of reasoning demands and prior knowledge on EFL learners' oral CAF. The study captured several stimulating findings regarding the influences of reasoning demands and prior knowledge on the complexity, accuracy, and the fluency of Iranian EFL learners' oral proficiency. The results of this study showed that both these two conditions (i.e., reasoning demands as a resource-directing factor and prior knowledge as a resource-dispersing factor) affected accuracy and complexity whereas their effect for fluency did not reach statistical significance.

\subsection{The Effect of Reasoning Demands on Triadic Aspects of Oral Production}

The first research question of the current study addressed the effects of reasoning demands on the accuracy, complexity and fluency of EFL learners' oral performance. In response to this question, three hypotheses were formulated. As for the first hypothesis, it was found that complexity was significantly advantaged by reasoning demands. Thus, in this regard, the obtained results with regard to complexity were consistent with the complexity in other studies such as Yuan and Ellis's (2003) and Ellis and Yuan's (2005) which used the same measure as ours. With regard to the second hypothesis i.e. "reasoning demands do not have any effects on accuracy", it should be mentioned that the results are fairly consistent and clear: it was revealed that learners' accuracy noticeably enhanced from pretest to posttest. This finding is congruent with that of accuracy not only in Yuan and Ellis's (2003) and Ellis and Yuan's (2005), but also in studies done by Ahmadian (2012a, 2012b). The third hypothesis was concerned with the effects of reasoning demands on the fluency of L2 speakers. Concerning this hypothesis, the achieved results failed to show a statistically significant effect which seemed to run counter to the results of the studies such as Bygate $(1996,2001)$, Lynch and Maclean (2000) with regard to fluency, yet our results of fluency were compatible with some other previous studies like Yuan and Ellis's (2003) and Ellis and Yuan's (2005).

\subsection{The Effect of Prior Knowledge on Triadic Aspects of Oral Production}

The second research question of the study addressed the role of prior knowledge in accuracy, complexity and fluency of Iranian EFL learners' oral production. Thus, the fourth, fifth, and sixth hypotheses were made in reply to this question. The fourth hypothesis claimed that prior knowledge had no significant effect on Iranian EFL learners' complexity of oral production. Regarding this proposition, it was demonstrated that prior knowledge caused a statistically significant impact on the complexity of L2 learners' oral production. Such a finding is in contrast with the results obtained from Ahmadian et.al. (2012a) in which prior knowledge had no positive effect on the complexity of learners, but are consistent with Foster and Skehan (1996) and Skehan and Foster (1997) that a tight narrative structure supports complexity in L2 performance. The fifth hypothesis stated that prior knowledge had no effects on the accuracy of Iranian EFL learners. In conformity with the results mentioned, accuracy was significantly influenced by prior knowledge which is in line with the finding of Matthiessen and Thompson (1988), Tavakoli (2009), Tavakoli and Skehan (2005). The sixth hypothesis which addressed the effect of prior knowledge on fluency was not confirmed. In this regard, it was mentioned in number of studies done by Tavakoli (2009) and Tavakoli and Skehan (2005) that prior knowledge consistently produces more 
fluent performances which is in sharp contrast to the obtained result in our study, which is in conformity with Tavakoli and Foster (2008).

\subsection{Conclusion}

It can be concluded that reasoning demand as a resource-directing factor in the column of cognitive complexity had a positive effect on the accuracy and complexity of EFL learners' oral production whereas their fluency was not significantly affected. Furthermore, learners under prior knowledge condition significantly improved in both accuracy and complexity aspects while the changes in their fluency did not reach statistical significance. Hence, on the condition that these strategies are being applied in our classes, they might be fruitful and help learner improve their oral performance abilities (specifically complexity and accuracy). Thus, in order to improve the fluency of L2 oral production, teachers and L2 practitioners will have to manipulate the resource-directing and resource-dispersing dimensions of tasks used in the present study, or to think of other potentially useful factors.

\section{References}

Ahmadian, M. J. (2012a). The effects of guided careful online planning on complexity, accuracy and fluency in intermediate EFL learners' oral production: The case of English articles. Language Teaching Research, 16(1), 129-149. https://doi.org/10.1177/1362168811425433

Ahmadian, M. J. (2012b). The relationship between working memory capacity and L2 oral performance under task-based careful online planning condition. TESOL Quarterly, 46(1), 165-175. https://doi.org/10.1002/tesq.8

Bygate, M. (1996). Effects of task repetition: appraising the developing language of learners. In J. Willis \& D. Willis (Eds.), Challenge and change in language teaching (pp. 136-146). Oxford: Heinemann.

Bygate, M. (2001). Speaking. In R. Carter \& D. Nunan (Eds.), The Cambridge guide to teaching English to speakers of other languages (pp. 14-21). Cambridge: Cambridge University Press. https://doi.org/10.1017/CBO9780511667206.003

Bygate, M. S., \& Skehan, P.P. \& Swain, M. (2001). Researching pedagogic tasks second language learning, teaching and testing. New York, NY: Routledge.

Candlin, C., \& Murphy, D. (1987). Language learning tasks. New York, NY: Englewoods Cliffs.

Ellis, R. (2003). Task-based language learning and teaching. New York: Oxford University Press.

Ellis, R., \& Barkhuizen, G. (2005). Analysing learner language. Oxford University Press.

Ellis, R., \& Yuan, F. (2005). The effects of careful within-task planning on oral and written task performance. In R. Ellis (Ed.), Planning and task performance in a second language, 11, 167-192. https://doi.org/10.1075/11lt.11.11ell

Foster, P., \& Skehan. P. (1996). The influence of planning on performance in task- based learning. Studies in Second Language Acquisition, 18(3), 299-324. https://doi.org/10.1017/S0272263100015047

Gilabert, R. (2007). The simultaneous manipulation of task complexity along planning time and [+/Here-and-Now]: Effects on L2 oral production. In M. P. Garcia Mayo (Ed.), Investigating tasks in formal language learning (pp. 44-68). Buffalo, NY: Multilingual Matters.

Ishikawa, T. (2007). The effect of manipulating task complexity along the [+/-Here-and-Now] dimension on L2 written narrative discourse. Investigating tasks in formal language learning, 136-156.

Iwashita, N., McNamara, T., \& Elder, C. (2001) Can we predict task difficulty in an oral proficiency test? Exploring the potential of an information-processing approach to task design. Language Learning, 51(3), 401-436. https://doi.org/10.1111/0023-8333.00160

Kuiken, F., \& Vedder, I. (2007). Cognitive task complexity and linguistic performance in French L2 writing. In M. P. Garcı'a Mayo (Ed.), Investigating tasks in formal language learning (pp. 117-135). Clevedon, UK: Multilingual Matters.

Kuiken, F., Mos, M., \& Vedder, I. (2005). Cognitive task complexity and second language writing performance. Eurosla yearbook, 5(1), 195-222. https://doi.org/10.1075/eurosla.5.10kui

Long, M. (1989). Task, group and task-group interactions. University of Hawaii Working Papers in ESL, 8(2), $1-26$.

Lynch, T., \& Maclean, J. (2000). Exploring the benefits of task repetition and recycling for classroom language learning. Language Teaching Research, 4(3), 221-250. https://doi.org/10.1177/136216880000400303 
Matthiessen, C., \& Thompson, S. A. (1988). The structure of discourse and 'subordination'. Clause combining in grammar and discourse, 18, 275-329. https://doi.org/10.1075/tsl.18.12mat

McLaughlin, B., \& Heredia, R. (1996). Information-processing approaches to research on second language acquisition and use. In W. C. Ritchie \& T. K. Bhatia (Eds.), Handbook of second language acquisition (pp. 213-228). San Diego: Academic Press. https://doi.org/10.1016/B978-012589042-7/50009-8

Nunan, D. (1989). Designing tasks for the communicative classroom. Cambridge: Cambridge University Press.

Robinson, P. (2001a). Cognition and second language instruction. Cambridge: Cambridge University Press. https://doi.org/10.1017/CBO9781139524780

Robinson, P. (2001b). Task complexity, cognitive resources, and syllabus design: A triadic framework for examining task influences on SLA. In P. Robinson (Ed.), Cognition and second language instruction. Cambridge: Cambridge University Press. https://doi.org/10.1017/CBO9781139524780.012

Robinson, P. (2003). Attention and memory during SLA: SLA and cognitive science. In C. J. Doughty \& M. H. Long (Eds.), The handbook of second language acquisition (pp. 631-678). Malden, MA: Blackwell. https://doi.org/10.1002/9780470756492.ch19

Robinson, P. (2005) Cognitive complexity and task sequencing: Studies in a componential framework for second language task design. International Review of Applied Linguistics 43(1), 1-32. https://doi.org/10.1515/iral.2005.43.1.1

Robinson, P. (2007). Task complexity, theory of mind, and intentional reasoning: Effects on L2 speech production, intention, uptake, and perceptions of task difficulty. International Review of Applied Linguistics in Language Teaching (IRAL), 45(3), 193-213. https://doi.org/10.1515/iral.2007.009

Robinson, P., Ting, S. C. C., \& Urwin, J. J. (1995). Investigating second language task complexity. RELC Journal, 26(2), 62-79. https://doi.org/10.1177/003368829502600204

Rubinstein, J. S., Meyer, D. E., \& Evans, J. E. (2001). Executive control of cognitive processes in task switching. Journal of experimental psychology: human perception and performance, 27(4), 763. https://doi.org/10.1037/0096-1523.27.4.763

Sanders, A. F. (1998). Elements of human performance. London: Lawrence Erlbaum Associates

Skehan, P. (1996). A framework for the implementation of task-based instruction. Applied Linguistics, 17(1), 38-62. https://doi.org/10.1093/applin/17.1.38

Skehan, P. (1998). Task-based instruction. Annual Review of Applied Linguistics, 18, 268-286. https://doi.org/10.1017/S0267190500003585

Skehan, P., \& Foster, P. (1997). Task type and task processing conditions as influences on foreign language performance. Language Teaching Research, 1, 185-211. https://doi.org/10.1177/136216889700100302

Skehan, P., \& Foster, P. (1999). The influence of task structure and processing conditions on narrative retellings. Language Learning, 49(1), 93-120. https://doi.org/10.1111/1467-9922.00071

Skehan, P., \& Foster, P. (2001). Cognition and tasks. Cognition and second language instruction, 183-205. https://doi.org/10.1017/CBO9781139524780.009

Tavakoli, P. (2009). Assessing L2 task performance: Understanding effects of task design. System, 37(3), 482-495. https://doi.org/10.1016/j.system.2009.02.013

Tavakoli, P., \& Foster, P. (2008). Task design and second language performance: The effect of narrative type on learner output. Language Learning, 58(2), 439-73. https://doi.org/10.1111/j.1467-9922.2008.00446.x

Tavakoli, P., \& Skehan, P. (2005). Strategic planning, task structure, and performance testing. In R. Ellis (Ed.), Planning and task-performance in a second language (pp. 239-73). Amsterdam: John Benjamins. https://doi.org/10.1075/11lt.11.15tav

Yuan, F. \& Ellis, R. (2003). The effect of pre-task planning and online planning on fluency, complexity, and accuracy in L2 oral production. Applied Linguistics, 24, 1-27. https://doi.org/10.1017/S0272263104026130

\section{Copyrights}

Copyright for this article is retained by the author, with first publication rights granted to the journal.

This is an open-access article distributed under the terms and conditions of the Creative Commons Attribution license (http://creativecommons.org/licenses/by/4.0/). 